\title{
Evaluation of melatonin treatment in primary culture of canine mammary tumors
}

\author{
JULIANA RAMOS LOPES ${ }^{1,2}$, LARISSA BAZELA MASCHIO ${ }^{1,2}$, BRUNA VICTORASSO JARDIM-PERASSI ${ }^{1,2}$ \\ MARINA GOBBE MOSCHETTA ${ }^{2,3}$, LÍVIA CARVALHO FERREIRA ${ }^{1,2}$, GUSTAVO RODRIGUES MARTINS ${ }^{2,3}$, \\ GABRIELA BOTTARO GELALETI $^{1,2}$ and DEBORA APARECIDA PIRES DE CAMPOS ZUCCARI ${ }^{2,4}$ \\ ${ }^{1}$ Post-graduate Program in Genetics, São Paulo State University (UNESP); ${ }^{2}$ Laboratory of Molecular Research \\ in Cancer (LIMC), ${ }^{3}$ Post-graduate Program in Health Sciences, and ${ }^{4}$ Department of Molecular Biology, \\ Faculty of Medicine of São José do Rio Preto (FAMERP), São José do Rio Preto, SP, Brazil
}

Received May 16, 2014; Accepted September 22, 2014

DOI: $10.3892 /$ or.2014.3596

\begin{abstract}
Mammary neoplasias are the most common tumors observed in female dogs. Identification of these tumors is valuable in order to identify beneficial therapeutic agents as alternative treatments for this tumor type. Oral administration of melatonin appears to exert an oncostatic effect on mammary neoplasia and may have a possible mechanism of action through its interaction with estrogen receptors on epithelial cells. Hence, we analyzed the potential therapeutic value of melatonin in tumors that are estrogen-dependent or -independent, and established a relationship of its action with the expression of the melatonin receptors $M T 1$ and $M T 2$. Furthermore, we analyzed the rate of cell proliferation and apoptosis after treatment with melatonin. Cell cultures were performed using 10 canine mammary tumor fragments and were divided into estrogen receptor (ER)-positive and ER-negative tumors. The results showed that both ER-positive and ER-negative tumors had decreased cell viability and proliferation after treatment with melatonin $(\mathrm{p}<0.05)$, although treatment was more effective in the ER-positive tumors. Analysis of the relative expression of the MT1 and MT2 genes by quantitative PCR was performed and the data were compared with the expression of ER in 24 canine mammary tumors and the cellular response to melatonin in 10 samples. MT1 was overexpressed in ER-positive tumors $(\mathrm{p}<0.05)$, whereas MT2 was not expressed. Furthermore, melatonin treatment in ER-positive tumors showed an efficient oncostatic effect by inhibiting cell viability and proliferation and inducing apoptosis. These results suggest that melatonin decreased neoplastic mammary cell proliferation and viability and induced apoptosis, with
\end{abstract}

Correspondence to: Dr Debora Ap. Pires de Campos Zuccari, Laboratório de Investigação Molecular do Câncer (LIMC), Faculty of Medicine of São José do Rio Preto, Brigadeiro Faria Lima 5416, 15090-000 São José do Rio Preto, SP, Brazil

E-mail: debora.zuccari@famerp.br

Key words: melatonin, estrogen receptor, immunocytochemistry, MT1, MT2 greater efficacy in ER-positive tumors that have a high expression of melatonin receptor MT1. This is a strong evidence for the use of melatonin as a therapeutic agent for estrogendependent canine mammary tumors.

\section{Introduction}

Mammary neoplasms are the most common tumors observed in female dogs and are the main cause of mortality and morbidity (1). Mammary tumors in female dogs provide a suitable model for the study of cancer biology (2-4) and also for therapeutic agents, since these animals have tumors with epidemiological and clinical characteristics, as well as biological behavior similar to mammary carcinomas in women (5-7).

Many studies have attempted to individualize the behavior of breast carcinomas by tumor-specific characteristics, trying to predict whether or not a tumor will respond to proposed treatment $(8,9)$. Estrogen receptor (ER) and progesterone receptor $(\mathrm{PR})$ are both predictive and prognostic factors used in the clinic to customize the management of each breast cancer case (10). ER-positive and PR-positive mammary tumors have a better prognosis and capacity to respond to therapy (11).

In this sense, the identification of therapeutic agents that can interact with specific molecular markers and inhibit tumor progression are potentially useful. Exogenous administration of melatonin appears to play an important role in tumor growth inhibition $(12,13)$. The oncostatic properties of melatonin can be exerted through interference at different levels of the signaling pathways of estrogen (14). Melatonin may inhibit estradiol hormone precursors produced in the ovary, thereby reducing the mitogenic response of estrogen-dependent breast tumor cells (15). Particularly in breast cancer, estrogen and melatonin are co-regulators of cell proliferation. Estrogen promotes proliferation and invasiveness, whereas melatonin suppresses these effects by decreasing the mitogenic response in estrogen-dependent tumor cells (16). Thus, the antiestrogenic properties of melatonin are the basis of its oncostatic action in ER-positive breast cancer tumors $(17,18)$ and can be an excellent adjunct to drugs commonly used for the prevention of breast cancer (19). 
In addition, melatonin acts by inducing apoptosis. The induction of apoptosis by melatonin has been described in the last few years in particular cancer types involving different action mechanisms $(20,21)$. Melatonin exerts significant inhibition of apoptotic processes in normal tissues or non-neoplastic diseases and there is evidence that melatonin may promote apoptosis in several cancer cell lines (22). Eck et al (23) found that sequential treatment with melatonin and all-trans-retinoic acid inhibits the proliferation and induces apoptosis of MCF-7 cells by decreasing the protein levels of the death suppressor, $\mathrm{Bcl}-2$, and increasing, although with different time courses, the levels of death promoters, Bax and Bak (23).

Furthermore, melatonin may exert its physiologic effects through membrane receptors. This hormone binds to and activates MT1 and MT2 G-protein-coupled receptors (24). The activated MT1 and MT2 receptors can reduce proliferation of tumor cells (25). Much of the inhibitory effect of melatonin on breast cancer cell proliferation is related with its binding to receptors MT1 and MT2 $(26,27)$. Thus, melatonin and its receptors may provide a promising avenue for establishing new therapeutic approaches in human cancer (12). Furthermore, there are no studies in the literature, which relate canine mammary tumors with melatonin receptors. Therefore, we explored the potential therapeutic value of melatonin in canine estrogen-positive and estrogen-negative mammary tumors, and related its action to MT1 and MT2 expression.

\section{Materials and methods}

Sample characterization. Tumor samples were collected from 24 female dogs with mammary neoplasia during the years of 2011 and 2012. After tumor excision, the animals were followed up from 1 to 18 months, with a median of 540 days. During the follow-up time, the veterinarians evaluated tumor metastasis and recurrence, as well as the cause of death of the animals.

For histopathologic diagnostics, the tumor biopsies collected were classified according to Misdorp et al (28) by the Armed Forces Institute of Pathology (AFIP). The parameters employed for the classification of clinical tumor staging were in accordance with the TNM system (size, lymph node involvement, metastasis) established by WHO for canine mammary gland tumors [modified (29)]: tumor mass size (T): T1, $<3 \mathrm{~cm}$; T2, between 3 and $5 \mathrm{~cm}$; T3, $>5 \mathrm{~cm}$; lymph node involvement (N): N0, no apparent involvement; N1, unilateral involvement; N2, bilateral involvement; and distant metastasis (M): M0, no evident metastasis; M1, distant metastasis including non-regional lymph nodes. Clinical staging was assigned as I, II, III or IV according to the tumor extension and prognostic establishment.

The presence of local tumor recurrence, metastasis and death were described and the overall survival was determined from the date of diagnosis until the date of last follow-up or death. The cause of death was evaluated by the attending veterinarian and only female dogs that died of the illness were included in the group for the study. The dogs that had died of respiratory failure were diagnosed with lung metastasis as shown by X-ray. This study was approved by the Ethics Committee of the Faculdade de Medicina de São José do Rio Preto (protocol no. 001-005222/2010).
Immunohistochemistry technique. Tumor samples were embedded into paraffin blocks and cut to provide $3-\mu \mathrm{m}$ sections. The samples were prepared on silanized glass slides before the paraffin was removed. The sections were rehydrated in an ascending range of alcohol concentrations and incubated with $3 \%$ hydrogen peroxide for $30 \mathrm{~min}$. Antigenic recovery was made in a recipient at $95^{\circ} \mathrm{C}$ in buffer for $35 \mathrm{~min}$ for each specific antibody, and then the slides were covered with bovine serum albumin (BSA) and incubated with the primary antibody (Table I). After cooling, the slides were covered with BSA for $30 \mathrm{~min}$ and incubated at $4^{\circ} \mathrm{C}$ overnight with the antibodies. After being washed with phosphate-buffered saline (PBS) for 15 min, incubation was carried out with Starr Trek Universal HRP Detection kit (Medical Biocare, Concord, CA, USA), consisting of the secondary antibody 'anti-mouse, rabbit and goat immunoglobulin with biotin' for $1 \mathrm{~h}$ and 'streptoavidin complex with peroxidase' for $30 \mathrm{~min}$, followed by washes with PBS for $15 \mathrm{~min}$ and $0.5 \%$ of 3,3'-diaminobenzidine tetrahydrochloride (DAB; Signet ${ }^{\circledR}$ Laboratories, Dedham, MA, USA) was applied to the slides for $2-5 \mathrm{~min}$ at $20-22^{\circ} \mathrm{C}$. The slides were counterstained with Harris' hematoxylin for $40 \mathrm{~min}$. Negative controls were obtained by omitting the primary antibody, and human kidney or breast cancer tissues served as the internal positive control in every assay.

Immunohistochemistry quantification. The slides were photographed and the proteins were quantified using ImageJ software (NIH, Bethesda, MD, USA) at x40 magnification under a Nikon Eclipse E200 microscope. For each sample, three regions of the tumor tissue were selected and 20 points in the tumor cells were marked in each region. In this way 60 different points were analyzed in each sample to obtain an average relative intensity of immunoreactivity. The values were expressed in arbitrary units (a.u.) and the mean optical density (MOD) showing the specific immunostaining intensity at immunoreactive areas. Cases were considered positive for estrogen receptors when $>10 \%$ tumor cells had cytoplasmic staining (30).

\section{Cell culture}

In vitro study. The cell culture was performed with tumor biopsies of 10 dogs out of the 24 with mammary tumors from the immunohistochemistry and PCR study. The tumor biopsies were sliced into microfragments and incubated at $37^{\circ} \mathrm{C}$ in $5 \% \mathrm{CO}_{2}$ in Dulbecco's modified Eagle's medium (DMEM; Cultilab, São Paulo, Brazil) supplemented with 20\% fetal bovine serum (Cultilab), 1\% streptomycin/penicillin/ fungizone (Sigma-Aldrich, St. Louis, MO, USA), $200 \mu 1$ hydrocortisone (Sigma-Aldrich) and $10 \mu \mathrm{l}$ epidermal growth factor (EGF; Sigma-Aldrich). The cells were submitted to immunocytochemistry for confirmation of the epithelium origin, with the anti-cytokeratin antibody, resulting in a positive protein staining.

Cell viability by the 3-(4.5-dimethylthiazol-2-yl)-2.5-diphenyltetrazolium bromide (MTT) assay. The cells from each tumor biopsy were plated into 96 -well plates containing $3 \times 10^{3}$ cells/well and divided into 2 groups: control (untreated) and treatment with different concentrations of melatonin (SigmaAldrich) $(0.5,1,2,5$ and $10 \mathrm{mM})$ for $24 \mathrm{~h}$. Melatonin was 
Table I. Antibodies and dilutions.

\begin{tabular}{lllll}
\hline Antibody & \multicolumn{1}{c}{ Specificity } & Clone & Dilution & Company \\
\hline ER & Monoclonal (mouse) & 1 D5 & $1: 150$ & Santa Cruz \\
PR & Monoclonal (rabbit) & SP42 & $1: 400$ & Abcam \\
Her2/neu & Polyclonal (rabbit) & C-18 & $1: 800$ & Santa Cruz \\
Ki-67 & Monoclonal (rabbit) & SP6 & $1: 200$ & Biocare Medical \\
P53 & Monoclonal (mouse) & FPS392 & $1: 100$ & Santa Cruz \\
Caspase-3 & Polyclonal (rabbit) & N/A & $1: 1,000$ & Biocare Medical \\
\hline
\end{tabular}

ER, estrogen receptor; PR, progesterone receptor.

diluted in $0.05 \%$ ethanol. In the control cells, equivalent amounts of ethanol were added as vehicle. Thereafter, $10 \mu 1$ of MTT solution (Invitrogen Life Technologies, Carlsbad, CA, USA) was added to each well and the plates were incubated at $37^{\circ} \mathrm{C}$ for $4 \mathrm{~h}$. To solubilize the MTT formazan crystals, the cells were incubated with dimethylsulfoxide (DMSO; SigmaAldrich) for $10 \mathrm{~min}$ at $37^{\circ} \mathrm{C}$. Absorbance was measured at $540 \mathrm{~nm}$ by an ELISA reader (Thermo Plate, Waltham, MA, USA). Medium was used as background and subtracted from the samples. Cell viability (\%) was calculated for all groups compared to the control sample. All experimental samples were in triplicate.

Immunocytochemistry. To confirm the efficacy of the treatment with melatonin, immunocytochemistry was performed with the anti-caspase-3 and anti-Ki-67 antibodies. For the procedure, the canine mammary tumor cell line CMT-U229 was treated with $1 \mathrm{mM}$ of melatonin. Two treatment groups were established: Group I (control) containing only cells in culture medium and group II treated also with $1 \mathrm{mM}$ of melatonin. The cells were thus incubated for $24 \mathrm{~h}$. Initially, the whole content was taken from the bottles and the cells were washed with PBS. They were then incubated with paraformaldehyde $4 \%$ fixative and rinsed with PBS. Next, they were incubated with $3 \%$ hydrogen peroxide for $30 \mathrm{~min}$. Antigenic recovery was carried out in a recipient at $95^{\circ} \mathrm{C}$ in buffer for $35 \mathrm{~min}$ for each specific antibody, and then the slides were covered with BSA and incubated with the anti-caspase-3 and anti-Ki-67 primary antibodies (Table I). After cooling, the slides were covered with BSA for $30 \mathrm{~min}$ and incubated at $4^{\circ} \mathrm{C}$ overnight with the antibodies. They were then washed with PBS for 15 min and incubated with the EasyPath kit (Biocare Medical, Concord, CA, USA) composed of the secondary antibody. In the next stage, they were stabilized at room temperature, washed with PBS buffer solution, and incubated with the EasyPath kit (Erviegas, São Paulo, SP, Brazil) containing the secondary antibody (biotinylated anti-mouse, rabbit, goat immunoglobulins). They were once again rinsed with PBS and incubated with the tertiary antigen (peroxidasestreptavidin conjugates) and then rinsed one last time with PBS. The result was revealed using chromogenic substrate (DAB; Signet Laboratories), $1 \mathrm{drop} / \mathrm{ml}$ and hematoxylin for counterstaining. Finally, the apoptosis and cell proliferation indices were analyzed.

Apoptosis and cell proliferation indices. Tumors were categorized in relation to apoptosis and cellular proliferation according to the staining of caspase- 3 and $\mathrm{Ki}-67$, respectively. For analysis of immunocytochemistry slides, five areas were photographed at $\mathrm{x} 40$ magnification (center, bottom, top, left and right regions). Caspase-3- and $\mathrm{Ki}-67$-positive cells were counted using Image J. At least 75-100 neoplastic cells were counted. The cut-off of positivity was set as $5 \%$ of positive neoplastic cells.

Gene expression of MT1 and MT2. Quantitative RT-PCR tests were performed in triplicate using a System Step One Plus (Applied Biosystems, Foster City, CA, USA). The PCR reactions contained $100 \mathrm{ng}$ cDNA, $10 \mu \mathrm{l}$ TaqMan Universal Master Mix, $8 \mu 1$ of DEPC solution, $1 \mu 1$ TaqMan Gene Expression for MT1, MT2 and RPL8 (Applied Biosystems); and 100 ng cDNA, $10 \mu 1$ TaqMan Universal Master Mix (Applied Biosystems), $8 \mu \mathrm{l}$ of DEPC solution (Applied Biosystems), $100 \mathrm{nmol}$ of each primer, $250 \mathrm{nmol}$ of the probe for RPS19 were subjected to the following amplification scheme: $50^{\circ} \mathrm{C}$ for $2 \mathrm{~min}, 95^{\circ} \mathrm{C}$ for $10 \mathrm{~min}$, followed by 40 cycles of $95^{\circ} \mathrm{C}$ for $15 \mathrm{sec}$ and $60^{\circ} \mathrm{C}$ for $1 \mathrm{~min}$.

Endogenous control RPS19 (Applied Biosystems) and $R P L 8$ were used for normalization. The relative expression values of the genes of interest were determined with Data Assist v3.0, by the quantification method related to the average of the normalizing genes used as endogenous control $(\Delta \Delta \mathrm{Ct})(31)$. All samples were tested in triplicate and the negative control was included in each reaction.

The gene RPS19 was researched, selected in PUBMED (http://www.ncbi.nlm.nih. gov/entrez), and synthesized from canine messenger RNA already sequenced and confirmed. The design used the program Primer Express. Primers used for amplification were: RPS19 (endogenous control) sense (5'-GCCTTCCTCAAAAAGTCTGGG-3'), antisense (5'-GCT TGCTCCCTACGATGAGAAC-3') and probe (5'-CCCTGAA TGGGTGGAC-3') (GenBank: NG_006583.3). For analyses of the expression of other genes, TaqMan assays (Applied Biosystems) were used: MT1 (Cf02705306_g1), MT2 (Cf02730504_g1) and RPL8 (endogenous control) (Cf02663820_m1).

For analyses of $M T 1$ and $M T 2$ expression, the relative quantitation (RQ) value for the control group (used as reference) was established as unity and are expressed in log10 scale as zero.

Statistical analysis. The results were submitted for descriptive analysis to determine normality. For samples with normal 
Table II. Correlation between the five antibody stains with the clinical and pathological factors of the female dogs with mammary tumors.

\begin{tabular}{|c|c|c|c|c|c|c|}
\hline $\begin{array}{l}\text { Clinicopathological } \\
\text { factors }\end{array}$ & $\begin{array}{l}\text { No. of female } \\
\text { dogs }(\%)\end{array}$ & ER & PR & Ki-67 & P53 & Her2/neu \\
\hline \multicolumn{7}{|l|}{ Age (years) } \\
\hline$\geq 10$ & $14(58)$ & $165.7 \pm 4.145$ & $153.2 \pm 4.040$ & $162.6 \pm 6.074$ & $153.9 \pm 2.695$ & $166.8 \pm 5.046$ \\
\hline$<10$ & $10(42)$ & $148.0 \pm 6.011$ & $152.5 \pm 5.278$ & $160.5 \pm 6.425$ & $160.0 \pm 5.363$ & $158.3 \pm 8.227$ \\
\hline P-value & & $\mathbf{0 . 0 1 9 3}^{\mathrm{a}}$ & 0.9131 & 0.8215 & 0.2817 & 0.3564 \\
\hline \multicolumn{7}{|l|}{ Time course } \\
\hline$\leq 6$ months & $11(46)$ & $156.2 \pm 5.486$ & $150.4 \pm 4.560$ & $166.7 \pm 5.039$ & $154.9 \pm 4.030$ & $160.3 \pm 7.864$ \\
\hline$>6$ months & $13(54)$ & $158.1 \pm 5.275$ & $155.1 \pm 4.750$ & $157.4 \pm 7.237$ & $157.1 \pm 3.977$ & $165.0 \pm 5.516$ \\
\hline P-value & & 0.7987 & 0.4908 & 0.3181 & 0.7052 & 0.6165 \\
\hline \multicolumn{7}{|l|}{ Clinical stage } \\
\hline I and II & $11(54)$ & $158.9 \pm 4.677$ & $154.7 \pm 5.635$ & $167.7 \pm 5.688$ & $157.0 \pm 3.944$ & $171.5 \pm 5.437$ \\
\hline III and IV & $13(46)$ & $155.9 \pm 5.782$ & $151.5 \pm 3.909$ & $154.5 \pm 6.628$ & $155.3 \pm 4.045$ & $157.1 \pm 6.353$ \\
\hline P-value & & 0.6978 & 0.6379 & 0.1561 & 0.7621 & 0.1087 \\
\hline \multicolumn{7}{|l|}{ Number of nodules } \\
\hline Multiple & $12(50)$ & $153.1 \pm 5.477$ & $152.3 \pm 5.165$ & $158.1 \pm 8.094$ & $157.0 \pm 4.437$ & $161.3 \pm 5.520$ \\
\hline Single & $12(50)$ & $161.4 \pm 5.003$ & $153.6 \pm 4.268$ & $165.3 \pm 4.370$ & $155.2 \pm 3.550$ & $164.3 \pm 7.592$ \\
\hline P-value & & 0.2769 & 0.8378 & 0.4401 & 0.7556 & 0.7528 \\
\hline \multicolumn{7}{|c|}{ Tumor vascularization } \\
\hline Abundant & $7(29)$ & $163.8 \pm 6.918$ & $150.0 \pm 5.949$ & $164.0 \pm 7.370$ & $159.4 \pm 3.613$ & $163.6 \pm 6.683$ \\
\hline Moderate & $17(71)$ & $154.5 \pm 4.386$ & $152.8 \pm 3.993$ & $160.7 \pm 5.799$ & $154.7 \pm 3.651$ & $162.5 \pm 6.003$ \\
\hline P-value & & 0.2645 & 0.7022 & 0.7530 & 0.4579 & 0.9175 \\
\hline \multicolumn{7}{|l|}{ Tumor ulceration } \\
\hline Yes & $3(12)$ & $164.7 \pm 11.04$ & $161.2 \pm 4.100$ & $172.7 \pm 6.015$ & $161.7 \pm 2.159$ & $167.5 \pm 4.310$ \\
\hline No & $21(88)$ & $156.2 \pm 4.009$ & $151.8 \pm 3.652$ & $160.1 \pm 5.082$ & $155.3 \pm 3.141$ & $162.2 \pm 5.232$ \\
\hline P-value & & 0.4598 & 0.3504 & 0.3721 & 0.4548 & 0.7105 \\
\hline \multicolumn{7}{|l|}{ Metastasis } \\
\hline Yes & $2(8)$ & $145.8 \pm 31.97$ & $130.1 \pm 2.308$ & $173.9 \pm 8.266$ & $144.2 \pm 12.27$ & $171.5 \pm 13.85$ \\
\hline No & $22(92)$ & $158.3 \pm 3.401$ & $155.0 \pm 3.221$ & $160.6 \pm 4.883$ & $157.1 \pm 2.821$ & $162.0 \pm 4.910$ \\
\hline P-value & & 0.3663 & 0.0327 & 0.4298 & 0.2070 & 0.5816 \\
\hline \multicolumn{7}{|l|}{ Censure } \\
\hline Living & $21(87)$ & $154.6 \pm 3.904$ & $152.6 \pm 3.502$ & $159.8 \pm 5.055$ & $155.4 \pm 3.137$ & $163.5 \pm 5.200$ \\
\hline Death & $3(13)$ & $175.5 \pm 4.685$ & $155.1 \pm 11.33$ & $174.6 \pm 5.368$ & $160.8 \pm 3.491$ & $158.5 \pm 6.580$ \\
\hline P-value & & 0.0628 & 0.8144 & 0.2930 & 0.5328 & 0.7282 \\
\hline \multicolumn{7}{|l|}{ Tumor recurrence } \\
\hline Yes & $5(21)$ & $152.5 \pm 10.82$ & $153.5 \pm 5.798$ & $162.0 \pm 11.70$ & $156.7 \pm 6.109$ & $146.4 \pm 9.696$ \\
\hline No & $19(79)$ & $158.5 \pm 3.895$ & $152.8 \pm 3.923$ & $161.6 \pm 5.057$ & $155.9 \pm 3.214$ & $167.2 \pm 4.863$ \\
\hline P-value & & 0.5238 & 0.9391 & 0.9690 & 0.9096 & 0.0645 \\
\hline
\end{tabular}

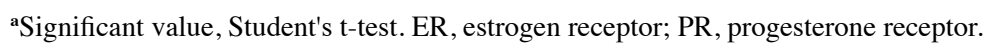

distribution, the Student's t-test or ANOVA was used, followed by the Bonferroni test. The Kruskal-Wallis test was used for samples with non-normal distributions. For all tests, $\mathrm{p}<0.05$ was considered significant. GraphPad Prism4 (GraphPad Software, La Jolla, CA) and DataAssist 3.0 (Applied Biosystems) were used for the analyses.

\section{Results}

Clinical data. The age of the animals varied from 7 to 14 years (mean, 10 years). There was a prevalence of malignant tumors, which were represented by $9(37.5 \%)$ tubulopapillary carcinomas, $5(20.8 \%)$ carcinomas of mixed type, 1 (4.2\%) carcinosarcoma, $1(4.2 \%)$ in situ carcinoma, 1 (4.2\%) sarcoma, $1(4.2 \%)$ adenocarcinoma and $1(4.2 \%)$ solid carcinoma with tubular areas. Benign changes were represented by $2(8.3 \%)$ benign mixed tumors, 1 (4.2\%) high-grade dysplasia, 1 (4.2\%) papilloma and $1(4.2 \%)$ adenoma. Among the clinicopathological characteristics, there was a prevalence of tumors with clinical stage III and IV (46\%); 21 (88\%) tumors had the absence of ulceration, 13 (54\%) tumors had time course (range among the observation of the anomaly by the owner/injury 


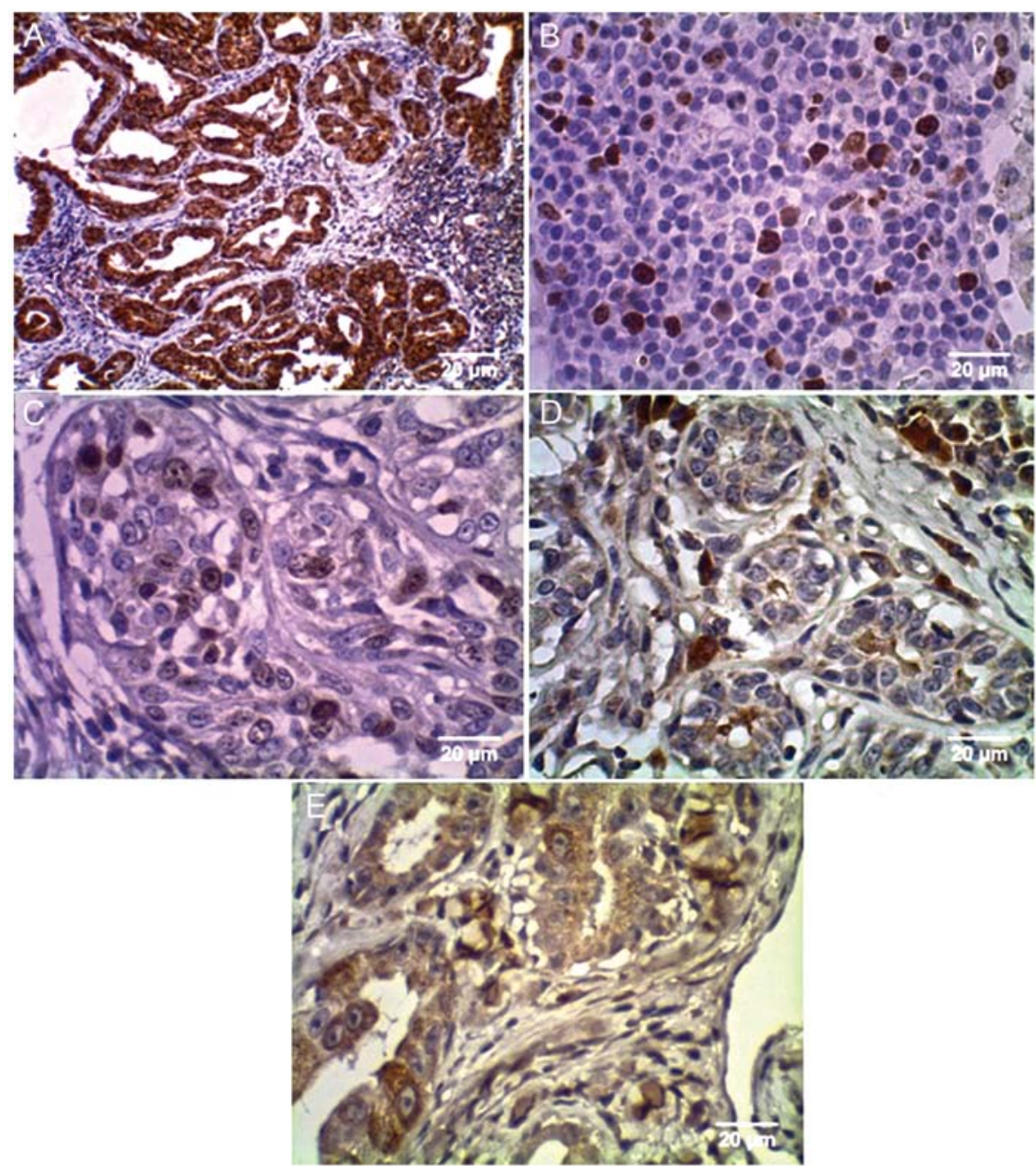

Figure 1. Photomicrographs of the immunohistochemical staining procedure demonstrating antibody staining in female dogs with mammary tumors. Nikon Eclipse E200, magnification x40. (A) Her2/neu immunostaining (in situ carcinoma). (B) Ki-67 immunostaining (carcinosarcoma). (C) p53 immunostaining (in situ carcinoma). (D) Estrogen receptor (ER) immunostaining (high-grade dysplasia). (E) Progesterone receptor (PR) immunostaining (tubulopapillary carcinoma).

diagnosis by the veterinarian and removal by surgery) greater than 6 months, $17(71 \%)$ tumors showed moderate vascularization, $19(79 \%)$ had the absence of tumor recurrence and $22(92 \%)$ did not show metastasis. All data are documented in Table II.

\section{Immunohistochemistry study}

Correlation between the expression of prognostic markers and clinical and pathological characteristics of the female dogs. The panel of classic prognostic markers, analyzed by the immunohistochemical expression of ER, PR, Her2/neu, p53 and cell proliferation marker, Ki-67, were determined for all animal casex (Fig. 1).

Thirteen of $24(54 \%)$ tumors were positive for ER, with immunostaining in the nucleus and cytoplasm (Fig. 1). PR immunostaining was cytoplasmic; Ki-67 and p53 were evident in the nucleus of the neoplastic cells while Her $2 /$ neu presented staining in the membrane of tumor cells (Fig. 1).

There was no correlation between ER expression and clinical characteristics and pathology including time course, clinical stage, number of nodules, tumor vascularization, ulceration and metastasis ( $p>0.05$; Table II). However, the high expression of ER had a statistically significant correlation with age ( $\mathrm{p}=0.02$; Table II). The expression of ER, PR, HER2/neu, p53 and Ki-67 by immunohistochemistry was compared with the clinical development of the female dogs, including metastasis and death. PR expression was increased in the female dogs that did not present with metastasis $(p=0.03$; Table II). There was no significant statistical relationship between the analyzed variables and the expression of the enzymes HER2/ neu, p53 and Ki-67 (p>0.05; Table II).

\section{MTT assay}

In vitro study. Ten tumor specimens were analyzed from the 24 samples used for immunohistochemistry and PCR. The canine mammary tumors were divided into ER-positive and ERnegative tumors. To target the antitumor activity by melatonin, we evaluated the cell viability in primary culture of canine mammary neoplasms by MTT assay following melatonin treatment. As shown in Fig. 2, cell viability was decreased in both the ERpositive and ER-negative tumors at all melatonin concentrations tested when compared to the control $(\mathrm{p}<0.05)$ after $24 \mathrm{~h}$. However, in the ER-positive tumors, the pharmacological concentration of $1 \mathrm{mM}$ of melatonin significantly decreased the cell viability and the same occurred with the highest concentration of melatonin $(10 \mathrm{mM})$ in ER-negative tumors ( $<<0.05$; Fig. 2). 

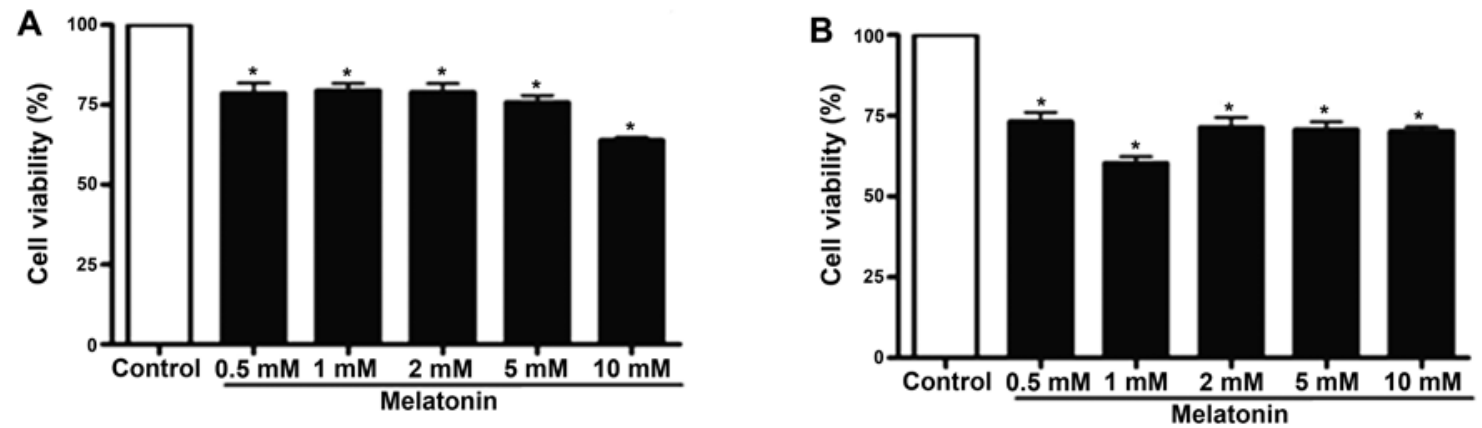

Figure 2. Inhibitory effect of melatonin on cell viability of the primary culture cells from the mammary tumors of the female dogs. The cells were treated with five different concentrations of melatonin for $24 \mathrm{~h}$ and cell viability was measured by MTT assay. The white column represents the control without treatment. The black columns correspond to the cells treated with the indicated concentrations of melatonin. Data are shown as mean \pm SD. (A) Estrogen receptor (ER)negative female canine mammary tumors. (B) ER-positive female canine mammary tumors. "Significant value, ANOVA followed by Bonferroni.

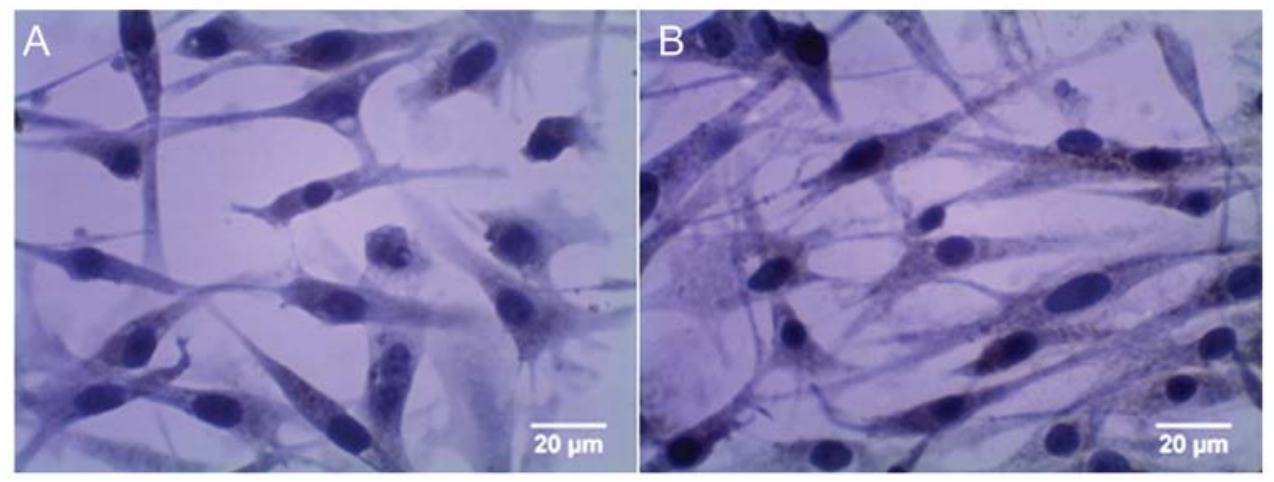

Figure 3. Photomicrographs of the immunocytochemical reaction for caspase-3 in the CMT-U229 cell line. (A) Cells without treatment (control). (B) Cells treated with $1 \mathrm{mM}$ of melatonin. Magnification, x400.
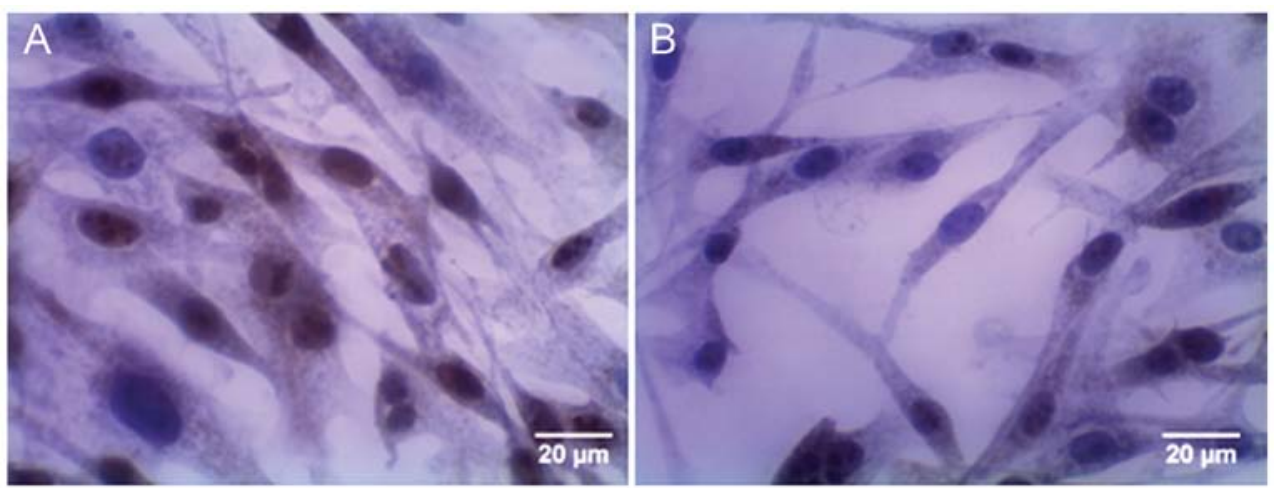

Figure 4. Photomicrographs of the immunocytochemical reaction for Ki-67 in the CMT-U229 cell line. (A) Cells without treatment (control). (B) Cells treated with $1 \mathrm{mM}$ of melatonin. Magnification, x400.

Apoptosis and cell proliferation. The level of caspase- 3 immunostaining and the rate of apoptosis in the group treated with $1 \mathrm{mM}$ of melatonin were higher than these values in the control cell group (Fig. 3). Regarding Ki-67, numerous positive cells were observed in the control group, whereas few positive cells were observed in the group treated with $1 \mathrm{mM}$ of melatonin (Fig 4).

MT1 and MT2 gene expression analysis. In order to compare the expression of the receptors MT1 and MT2 with ER expression and with the cellular response to melatonin, analysis of the relative expression of the $M T 1$ and $M T 2$ genes by quantitative PCR was carried out and the data were compared with the expression of ER in 24 canine mammary tumors and the cellular response to melatonin in the 10 samples.

The RQ value for the control group (used as a calibrator) was established as 1 and is shown on a $\log 10$ scale as zero.

Results showed that the MT1 gene was overexpressed in the ER-positive breast tumors compared to the ER-negative tumors ( $\mathrm{p}<0.05$; Fig. 5). Although the MT2 receptor was not detectable in the mammary tumors, it was expressed but apparently not fully functional ( $p>0.05$; Fig. 6). Furthermore, 


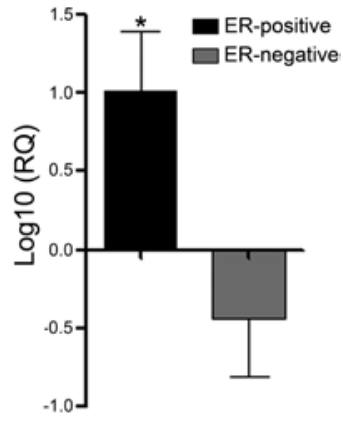

Figure 5. MT1 gene expression in estrogen receptor (ER)-positive and ER-negative female canine mammary tumors relative to normal tissues (considered as zero). Gene expression values are expressed on a $\log 10$ scale. "Significant value, Student's t-test.

melatonin treatment in the ER-positive tumors that overexpressed MT1 showed efficient an oncostatic effect by inhibiting cell viability.

\section{Discussion}

In the present study, we used an immunohistochemistry technique to examine the expression of the estrogen receptor in 10 breast tumor samples. We categorized these samples into two subgroup and compared the cellular response to melatonin by MTT assay and immunocytochemistry for the cell proliferation Ki-67 and apoptosis caspase-3 markers. We found that treatment with a pharmacological dose $(1 \mathrm{mM})$ of melatonin inhibited cell proliferation of ER-positive tumors. For ER-negative tumors the reduction in cell proliferation was observed at the highest dose of melatonin evaluated $(10 \mathrm{mM})$. However, the $10 \mathrm{mM}$ dose has been described as cytotoxic (32). According to Jung et al (32) treatment at pharmacological levels of melatonin $(8$ and $16 \mathrm{mM}$ ) in ER-negative (MDAMB-231) cells showed weak cytotoxicity. Melatonin has been described as able to inhibit the precursors of estradiol production, reducing the mitogenic response of ER-positive breast cancer cells (15). Rato et al (33) found that MCF-7 cells stimulated with estradiol had a high binding activity to the ER, which was prevented by treatment with melatonin suggesting their role in inhibition of the estrogen signaling pathway. Other authors also showed that melatonin inhibits proliferation of ER-positive breast cancer (MCF-7) cells $(11,14,23,34)$, but not ER-negative (MDA-MB-231) cells $(11,23)$. These studies indicate the positive relationship between the estrogen receptor and melatonin.

Furthermore, Eck et al (23) found that combined in vitro treatment of melatonin and all-trans-retinoic acid inhibited the growth of MCF-7 cells, but was ineffective against MDA-MB231 cells, also suggesting that this treatment be used only for estrogen-dependent mammary tumors. Consistent with our results, Leman et al (35) showed that melatonin at a pharmacological level $(1 \mathrm{mM})$ significantly decreased the proliferation of ER-positive breast cancer MCF-7 cells.

Cellular responses to melatonin in our study were related to ER-positive tumors and is in agreement with the literature.

Furthermore, additional routes of action of melatonin have been described. Some authors showed that melatonin induced apoptosis in MCF-7 cells, leading to decreased expression of the

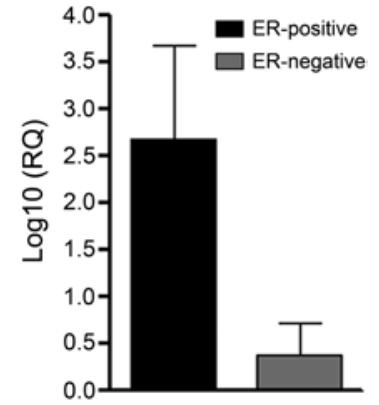

Figure 6. MT2 gene expression in estrogen receptor (ER)-positive and ER-negative female canine mammary tumors relative to normal tissues (considered as zero). Gene expression values are expressed on a $\log 10$ scale.

ER and the anti-apoptotic Bcl-2 protein, and increased expression of the pro-apoptotic Bax protein $(23,35)$. Our results showed that treatment with melatonin in ER-positive canine mammary (CMT-U229) cells increased the expression of caspase-3 protein. In the same way, Sanchez-Hidalgo et al (36) demonstrated that the treatment with melatonin in a panel of human cell lines increased the expression of caspase-3. Similarly, the results of Wang et al (37) showed that treatment with melatonin significantly increased the activities and the levels of caspase-3 protein, confirming the involvement of the caspase-3 pathway in melatonin-induced cell apoptosis indicating that caspase inhibitors can prevent melatonin-induced cell apoptosis in breast cancer cells. It was also suggested that the oncostatic actions of melatonin are mediated by MT1 melatonin receptor; melatonin binds to the high affinity G-protein linked, MT1 and MT2, reducing proliferation and inducing cell differentiation $(27,38)$. Furthermore, the expression of MT1 receptor was found to be positively correlated with the expression of the ER (26). Through activation of its receptor MT1, melatonin can suppress the development of cancer by a broad spectrum of mechanisms with and without the involvement of ER (38). Thus, in this study, the expression of MT1 and MT2 receptors in breast tumors of dogs was evaluated by real-time PCR. Furthermore, the expression of these receptors was compared to the expression of ER and cellular responses to melatonin. Our results showed that ER-positive tumors had a high expression of melatonin receptor MT1 and these tumors responded better to treatment with melatonin. However, these tumors did not express the MT2 receptor. Consistent with our results, other authors also showed that treatment with melatonin of ER-positive cancer cells that overexpress the melatonin receptor MT1 significantly decreased cell proliferation (11,3941). Moreover, Lai et al (26) verified high expression of the MT1 receptor in ER-positive MCF-7 cells and low expression in an ER-negative MDA-MB-231 cell line; however, both strains did not express the MT2 receptor. Similarly, Ram et al. (42) found a positive correlation between the MT1 receptor and the expression of ER- $\alpha$ in women with breast cancer. However, Yuan et al (11) indicated that both MCF-7 and MDA-MB-231 cells have a high expression of the MT1 receptor.

Breast cancer is one of the cancers with the highest mortality rate, thus new therapeutic approaches are needed to make the treatment more effective. Through this study it was possible to verify the action of melatonin in primary cell 
culture of canine mammary tumors. Thus, the results found in this study in canine mammary tumors were similar to those observed in strains of human breast cancer described in the literature, verifying that the canine mammary tumors are an excellent model for the study of breast cancer. Our results demonstrated that melatonin is able to reduce mammary tumor cell viability and proliferation and this reduction was most pronounced in ER-positive cells that overexpress the MT1 receptor. Thus, ER-positive tumors with high expression of MT1 respond better to treatment with melatonin. Furthermore, treatment with melatonin increased the apoptosis of canine mammary tumor cells. Taken together, our results showed that melatonin treatment inhibits cell viability, proliferation and induces apoptosis in canine mammary tumors. In this way, the therapeutic response of melatonin and the expression of MT1 receptor in estrogen-dependent breast tumor will greatly aid the potential of its use as a therapeutic agent in the treatment of this tumor type.

\section{Acknowledgements}

We thank Dr Cassali for the support in the reading and analyzing the slides, the veterinary practitioners from São José do Rio Preto and region and the owners of the dogs who cooperated with this study. The study was made possible by financial support received from FAPESP and CNPq.

\section{References}

1. Manuali E, De Giuseppe A, Feliziani F, et al: CA 15-3 cell lines and tissue expression in canine mammary cancer and the correlation between serum levels and tumour histological grade. BMC Vet Res 8: 86, 2012.

2. Schneider R: Comparison of age, sex, and incidence rates in human and canine breast cancer. Cancer 26: 419-426, 1970.

3. Mottolese M, Morelli L, Agrimi U, et al: Spontaneous canine mammary tumors. A model for monoclonal antibody diagnosis and treatment of human breast cancer. Lab Invest 71: 182-187, 1994.

4. Phillips JC, Lembcke L and Chamberlin T: A novel locus for canine osteosarcoma (OSA1) maps to CFA34, the canine orthologue of human 3q26. Genomics 96: 220-227, 2010.

5. MacEwen EG: Spontaneous tumors in dogs and cats: models for the study of cancer biology and treatment. Cancer Metastasis Rev 9: 125-136, 1990.

6. Peleteiro M: Tumores mamários na cadela e na gata. Revista Portuguesa de Ciências Veterinárias 89: 10-29, 1994.

7. Andrade FH, Figueiroa FC, Bersano PR, Bissacot DZ and Rocha NS: Malignant mammary tumor in female dogs: environmental contaminants. Diagn Pathol 5: 45, 2010.

8. Hamilton A and Hortobagyi G: Chemotherapy: what progress in the last 5 years? J Clin Oncol 23: 1760-1775, 2005.

9. Winer E, Gralow J, Diller L, et al: Clinical cancer advances 2008: major research advances in cancer treatment, prevention, and screening - a report from the American Society of Clinical Oncology. J Clin Oncol 27: 812-826, 2009.

10. Hsiao YH, Chou MC, Fowler C, Mason JT and Man YG: Breast cancer heterogeneity: mechanisms, proofs, and implications. J Cancer 1: 6-13, 2010.

11. Yuan L, Collins AR, Dai J, Dubocovich ML and Hill SM: MT(1) melatonin receptor overexpression enhances the growth suppressive effect of melatonin in human breast cancer cells. Mol Cell Endocrinol 192: 147-156, 2002.

12. Maganhin CC1, Carbonel AA, Hatty JH, et al: Melatonin effects on the female genital system: a brief review. Rev Assoc Med Bras 54: 267-271, 2008 (In Portuguese).

13. Luchetti F, Canonico B, Betti M, et al: Melatonin signaling and cell protection function. FASEB J 24: 3603-3624, 2010.

14. Cos S and Sánchez-Barceló EJ: Melatonin, experimental basis for a possible application in breast cancer prevention and treatment Histol Histopathol 15: 637-647, 2000.
15. Neto J and Scaldaferri P: Melatonina e câncer - revisão da literatura. Revista Brasileira Cancerol 51: 49-58, 2005 (In Portuguese).

16. Jablonska K, Pula B, Zemla A, et al: Expression of melatonin receptor MT1 in cells of human invasive ductal breast carcinoma. J Pineal Res 54: 334-345, 2013.

17. Mediavilla MD, Sanchez-Barcelo EJ, Tan DX, Manchester L and Reiter RJ: Basic mechanisms involved in the anti-cancer effects of melatonin. Curr Med Chem 17: 4462-4481, 2010.

18. Sturgeon SR, Doherty A, Reeves KW, et al: Urinary levels of melatonin and risk of postmenopausal breast cancer: Women's health initiative observational cohort. Cancer Epidemiol Biomarkers Prev 23: 629-637, 2014.

19. Sanchez-Barcelo EJ, Mediavilla MD, Alonso-Gonzalez C and Rueda N: Breast cancer therapy based on melatonin. Recent Pat Endocr Metab Immune Drug Discov 6: 108-116, 2012.

20. Bejarano I, Espino J, Barriga C, Reiter RJ, Pariente JA and Rodríguez AB: Pro-oxidant effect of melatonin in tumour leucocytes: relation with its cytotoxic and pro-apoptotic effects. Basic Clin Pharmacol Toxicol 108: 14-20, 2011.

21. Rodriguez C, Martín V, Herrera F, et al: Mechanisms involved in the pro-apoptotic effect of melatonin in cancer cells. Int J Mol Sci 14: 6597-6613, 2013

22. Cucina A, Proietti S, D'Anselmi F, et al: Evidence for a biphasic apoptotic pathway induced by melatonin in MCF-7 breast cancer cells. J Pineal Res 46: 172-180, 2009.

23. Eck KM, Yuan L, Duffy L, et al: A sequential treatment regimen with melatonin and all-trans retinoic acid induces apoptosis in MCF-7 tumour cells. Br J Cancer 77: 2129-2137, 1998.

24. Blask DE, Sauer LA and Dauchy RT: Melatonin as a chronobiotic/anticancer agent: cellular, biochemical, and molecular mechanisms of action and their implications for circadian-based cancer therapy. Curr Top Med Chem 2: 113-132, 2002.

25. Hardeland R, Pandi-Perumal SR and Cardinali DP: Melatonin. Int J Biochem Cell Biol 38: 313-316, 2006.

26. Lai L, Yuan L, Cheng Q, Dong C, Mao L and Hill SM: Alteration of the MT1 melatonin receptor gene and its expression in primary human breast tumors and breast cancer cell lines. Breast Cancer Res Treat 118: 293-305, 2009.

27. Grant SG, Melan MA, Latimer JJ and Witt-Enderby PA: Melatonin and breast cancer: cellular mechanisms, clinical studies and future perspectives. Expert Rev Mol Med 11: e5, 2009.

28. Misdorp W, Else R, Hellmen E and Lipscomb E: Definitions and explanatory notes. In: Who Histological Classification of Mammary Tumors of the Dog and Cat. Armed Forces Institute of Pathology, Washington, pp18-27, 1999.

29. Cassali G, Bertagnolli A, Lavalle G, et al: Perpectives for diagnosis, prognosis and treatment of mammary neoplasms in dogs. 34th World Small Animal Veterinary Congress WSAVA, São Paulo, 2009.

30. Li XR, Liu M, Zhang YJ, et al: ER, PgR, HER-2, Ki-67, topoisomerase II $\alpha$, and $\mathrm{nm} 23-\mathrm{H} 1$ proteins expression as predictors of pathological complete response to neoadjuvant chemotherapy for locally advanced breast cancer. Med Oncol 28 (Suppl 1): S48-S54, 2011.

31. Livak K and Schimittgen T: Analyzing real-time PCR data by the comparative C(T) method. Nature Protocols 3: 1101-1108, 2008.

32. Jung JW, Park SB, Lee SJ, Seo MS, Trosko JE and Kang KS: Metformin represses self-renewal of the human breast carcinoma stem cells via inhibition of estrogen receptor-mediated OCT4 expression. PLoS One 6: e28068, 2011.

33. Rato AG, Pedrero JG, Martinez MA, del Rio B, Lazo PS and Ramos S: Melatonin blocks the activation of estrogen receptor for DNA binding. FASEB J 13: 857-868, 1999.

34. Mao L, Cheng Q, Guardiola-Lemaître B, et al: In vitro and in vivo antitumor activity of melatonin receptor agonists. J Pineal Res 49: 210-221, 2010

35. Leman ES, Sisken BF, Zimmer S and Anderson KW: Studies of the interactions between melatonin and $2 \mathrm{~Hz}, 0.3 \mathrm{mT}$ PEMF on the proliferation and invasion of human breast cancer cells. Bioelectromagnetics 22: 178-184, 2001.

36. Sánchez-Hidalgo M, Guerrero JM, Villegas I, Packham G and de la Lastra CA: Melatonin, a natural programmed cell death inducer in cancer. Curr Med Chem 19: 3805-3821, 2012.

37. Wang J, Xiao X, Zhang Y, et al: Simultaneous modulation of COX-2, p300, Akt, and Apaf-1 signaling by melatonin to inhibit proliferation and induce apoptosis in breast cancer cells. J Pineal Res 53: 77-90, 2012.

38. Oprea-Ilies G, Haus E, Sackett-Lundeen L, et al: Expression of melatonin receptors in triple negative breast cancer (TNBC) in African American and Caucasian women: relation to survival. Breast Cancer Res Treat 137: 677-687, 2013. 
39. Collins A, Yuan L, Kiefer TL, Cheng Q, Lai L and Hill SM: Overexpression of the MT1 melatonin receptor in MCF-7 human breast cancer cells inhibits mammary tumor formation in nude mice. Cancer Lett 189: 49-57, 2003

40. Hill SM, Blask DE, Xiang S, et al: Melatonin and associated signaling pathways that control normal breast epithelium and breast cancer. J Mammary Gland Biol Neoplasia 16: 235-245, 2011.
41. Gonzalez-Angulo AM, Morales-Vasquez F and Hortobagyi GN: Overview of resistance to systemic therapy in patients with breast cancer. Adv Exp Med Biol 608: 1-22, 2007.

42. Ram PT, Kiefer T, Silverman M, Song Y, Brown GM and Hill SM: Estrogen receptor transactivation in MCF-7 breast cancer cells by melatonin and growth factors. Mol Cell Endocrinol 141: 53-64, 1998. 